\title{
Using multi-criteria decision making to highlight stakeholders' values in the corridor planning process
}

\author{
Bethany Stich \\ Mississippi State University ${ }^{a}$ \\ Charles G. O’Hara \\ Mississippi State University ${ }^{d}$
}

Joseph H. Holland

University of Mississippi ${ }^{b}$

\author{
Rodrigo A. A. Noberga \\ Mississippi State University ${ }^{c}$
}

\begin{abstract}
The processes for environmental review and public participation mandated by the National Environmental Policy Act (NEPA) and the 2005 Safe, Accountable, Flexible, Efficient Transportation Equity Act - A Legacy for Users (SAFETEA-LU) have become overly timeconsuming and costly in transportation planning. This paper focuses on the implementation of transportation policy, highlighting how its complex nature challenges the traditional policy process theories. Federal and local perspectives are used as a basis for top-down and bottomup implementation models. In addition, the authors discuss the conflicting nature of transportation policy implementation within decision processing and suggest an implementation tool that can aid transportation and planning professionals. The authors suggest that the use and integration of existing data from geospatial technologies and economic modeling can result in a visual Multiple Criteria Decision Making (MCDM) model that can aid in streamlining and enhancing the NEPA process, agency coordination, and public participation in different administration levels.
\end{abstract}

Keywords: Transportation planning; Policy implementation; GIS; MCDM; I-69

\section{Introduction}

From 1956 up until the current transportation legislation, transportation policy has evolved from relatively simple planning for federal and state highway construction and maintenance, to planning and maintaining a complex nationwide multimodal system. Transportation legislation requires multimodal planning, taking into account railways, airports, public transit systems, bikeways and walkways. Additionally, today's transportation legislation requires consideration for all of this as well as direct, indirect, and induced infrastructure impacts to the local culture, environment and economy. The authors assert that the implementation of transportation pol-

\footnotetext{
a Assistant professor, Dept. of Political Science and Public Administration, bstich@ps.msstate.edu

bVisiting professor, Dept. of Public Policy Leadership, jholland@ olemiss.edu

c Research assistant professor, Geosystems Research Institute, sal@gri. msstate.edu

d Associate research professor, Geosystems Research Institute, cgohara@gri.msstate.edu
}

icy is an exclusive action that deviates from the traditionally defined steps in the policy process (agenda setting, policy formulation, policy legitimation, policy implementation, policy and program evaluation, and policy change).

In addition, the National Environmental Policy Act (NEPA) process highlights the needs that lead "complexification" in transportation planning and implementation. Transportation and planning officials indicate that the NEPA process is an annoyance. Tripp and Alley (2004) report that a considerable percentage of transportation practitioners complain that conducting an adequate environmental review takes too much time and costs too much money. Conversely, environmental groups also are calling for reforms, including: more consideration of project alternatives by lead agencies; increased public participation in the NEPA process; and heightened judicial scrutiny of environmental review documents.

On one hand, agency officials indicate that NEPA has "lost its way." On the other hand, environmentalists argue that agency officials are not concerned with NEPA compliance, but instead focused on project implementation.

Copyright 2011 Bethany Stich, Joseph H. Holland, Rodrigo A. A. Nobrega, and Charles G. O’Hara.

Licensed under the Creative Commons Attribution - NonCommercial License 3.0. 
It is evident that the NEPA process is hindering transportation officials and environmentalists. For planners, the completion of Environmental Impact Statements (EIS) is too costly and too time-consuming; for environmentalists, the review process does not place a high enough priority on project alternatives or public participation. In addition to the EIS constraints, transportation project implementation has changed dramatically over the past decades. Instead of transportation planners focusing on the development of rural farmland, they are now challenged with the development of transportation projects that affect urban surroundings. Because of the complexities that exist within the framework of constructing new corridors in urban societies, planners need a systematic framework for decision making. With both sides of the debate calling for environmental review reforms and with streamlining emphasis in SAFETEA-LU, TEA-21, and Executive Order \#13274, an assessment of the implementation process is appropriate.

This article highlights the complex nature of transportation policy and planning and presents a systematic decisionmaking model that can aid planners. This research demonstrates how a decision-making tool was utilized in the NEPA process for the I-269 corridor. The discussion presented in this article is part of the project Streamlining Environmental and Planning Processes (SEPP) of the National Consortium on Remote Sensing in Transportation - Environmental Assessment (NCRST-EA), to conduct structured research to streamline the EIS process and promote the modernization of transportation systems. The project was sponsored by the U.S. Department of Transportation - Research and Innovative Technology Administration (USDOT-RITA). The goals, materials and findings addressed in the study area are tangible and compatible with Federal needs, as well as transferable to other locations.

This article has six main sections. First, is an overview of the "complexification" of transportation policy and planning due to current legislation. Second, the article highlights various transportation planning approaches that contribute to the complexity of implementing transportation policy. Next, a Multiple Criteria Decision Making (MCDM) model is presented as a tool to assist planners and stake holder during the planning and implementation process. Fourth, a discussion of the I-269 corridor is used to highlight various approaches and perspectives associated with the development and implementation of the corridor. Fifth, findings regarding the utilization of the MCDM model are presented, followed by concluding remarks.

\section{Transportation-based legislative background}

Today, transportation professionals are forced to navigate through a labyrinth of transportation planning procedures, legislation, and regulations that are intended to guide the planning process but in fact greatly complicate it.

The Interstate Highway Program, launched in 1956, has often been called the greatest public works projects in history. It also has been one of the United States' most successful federal programs, more than fulfilling President Dwight D. Eisenhower's prediction that it would "change the face of America." The Interstate era began with consensus about the desirability of building the Interstate System despite the spectrum of transportation interests and political shadings. However, by the end of the 1980s, the Interstate System was 97.5 percent completed, and after a 30-year period of accomplishments and controversies, that consensus had disappeared (Beimborn and Puentes 2003). Competition for federal funding, environmental concerns, and the fragmentation of authority made reauthorization of transportation legislation more challenging. At the same time, the transformation of state and local public transportation from a private industry to a public utility was creating another set of demands for federal funding.

The environmental movement, which had not entered the public consciousness in 1956 but was well established by the 1980s, had created national commitments that challenged the builders of the Interstate Highway System. These environmental commitments affected the debate on, and passage of, future transportation legislation.

The transportation goals of state and city officials often conflicted (Beimborn and Puentes 2003). As a result, federal policy began to shift. President Ronald Reagan, who favored a "New Federalism" in which activities he believed to be state responsibilities under the Constitution would be devolved to the states, began challenging the federal government's role in transportation. As a result, the Surface Transportation and Uniform Relocation Assistance Act of 1987 (STURAA), which became law on April 2, 1987, was widely viewed in Congress and in the transportation community as the last authorization bill of the Interstate era. It authorized $\$ 87.6$ billion in spending over five years, including $\$ 17$ billion for interstate construction that, the STURAA report said, "will provide the states sufficient funds to complete the system". As Senator Patrick Moynihan, who would continue to play a major role in the crafting of transportation legislation, told the Senate during the STURAA debate, "We are about to 
enter a new era." While everyone seemed to agree that the expiration of STURAA authorizations in 1991 would mark the end of the Interstate era, the exact nature of the post-Interstate era remained a mystery (Beimborn and Puentes 2003). Transportation planning was no longer simply a federal road building enterprise.

In early 1987, the Federal Highway Administration (FHWA) formed a task force known as the Futures Group, comprised of senior managers divided into 19 working groups. The charge from Executive Director Richard D. Morgan was to take a "strategic look" at the issues, trends, technologies and program options that would affect highways in the mid-range future (through 2005) and the long-range future (through 2020). This would be, he said, "a zero-based review;" If the Futures Group concluded that the federal-aid highway program was no longer needed after the completion of the Interstate System, so be it. Each working group created papers on aspects of surface transportation and the role of government as input for policy-makers (Weingroff 2001).

One of the most important events affecting transportation legislation occurred on November 15, 1990, when President George H.W. Bush signed the Clean Air Act Amendments of 1990 (CAAA). Although CAAA, like all bills, was a result of collaboration, it was chiefly the product of the Senate Committee on Environment and Public Works and especially Sen. Moynihan, chairman of the Water Resources, Transportation, and Infrastructure Subcommittee.

CAAA is yet another example of the complexification of transportation planning. It established criteria for attaining and maintaining National Ambient Air Quality Standards (NAAQS) developed by the U.S. Environmental Protection Agency (EPA) and mandated that transportation plans, programs, and projects conform to a "State Implementation Plan" for attaining the NAAQS compliance. Areas that had not met the NAAQS standards must act within a set time frame to reduce emissions. The EPA was given authority to impose sanctions, including the loss of federal-aid highway funds, to force compliance with the requirements of the NAAQS (ibid).

The provision of the CAAA reflected a growing public sentiment that the automobile was at the center of the air quality problem as well as many other problems. Although the CAAA established strong requirements, it provided no federal funds to state and local governments to help them comply. This new law, which placed surface transportation at the center of the fight for cleaner air, was a landmark product of the same committee that would develop the Inter-modal Surface Transportation Efficiency Act of 1991 (ISTEA). The committee, and especially Moynihan, would see ISTEA as an oppor- tunity to provide the funds and flexibility that were lacking in CAAA.

President George H. W. Bush declared ISTEA to be "the most important transportation bill since President Eisenhower started the Interstate System 35 years ago," and stated that " $[t]$ his bill also means investment in America's economic future, for an efficient transportation system is absolutely essential for a productive and efficient economy." He added that "The future of American transportation begins today" (Beimborn and Puentes 2003).

ISTEA and its reauthorizations, the Transportation Equity Act for the Twenty-First Century (TEA-21) (1998), and the Safe, Accountable, Flexible, Efficient Transportation Equity Act - A Legacy for Users (SAFETEA-LU) (2005), emphasized protecting the environment, identifying direct and indirect economic impacts, and including ample public participation in the transportation planning and programming processes. TEA-21 required not just state DOTs but also Metropolitan Planning Organizations (MPOs) to predict population and employment growth patterns and to involve interested citizens in the process. This legislation required environmental and economic impact reviews and public involvement opportunities during the development and amendment of several transportation planning activities-viz. metropolitan and rural long range transportation plans, Transportation Improvement Plans, the long range Statewide Transportation Plan, the State Transportation Improvement Program, and individual project plans. This article focuses on the implementation of this multifaceted, multidisciplinary and multipurpose transportation legislative mandate. The following section highlights how different approaches to transportation policy can draw attention to various tensions during the implementation process.

\section{Transportation policy}

Early literature on policy implementation highlights two contrasting implementation models : top-down and bottom-up. The top-down model does not account for lower-level actors, resource limitations, and various constraints that can hinder the policy implementation process (Bailey and Mosher 1968; Birkland 2005; Derthick 1970). In transportation planning, the legislation itself takes a top-down perspective. This legislation has a primary purpose which focuses on mid- and longterm national and regional mobility and economic development.

However, in the implementation of this legislation, there is also a bottom-up emphasis (Lipsky 1971). This implementa- 
tion model explains action that deals with the local issues of economic development and environmental justice, as well as the local resources that are included in the review of environmental impacts, and cultural and historical sites (Figure 1).
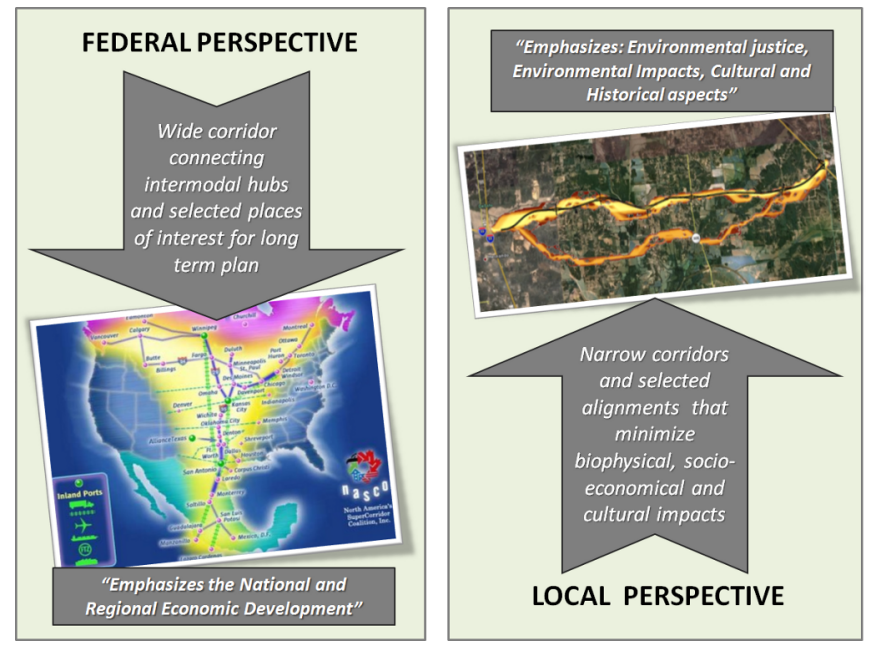

Figure 1: Top-down and bottom-up transportation planning approaches.

\subsection{The top-down approach: The demand for transportation corridors}

Today's transportation system faces safety issues, traffic congestion, freight movement constraints, the lack of intermodal connectivity, and environmental concerns. SAFETEA-LU attempts to address these issues and lay the groundwork for addressing future challenges. The federal top-down legislation was developed to provide opportunities for state and local planners and stakeholders to solve transportation concerns in the local community with a bottom-up approach. In addition, SAFETEA-LU encourages efficient and effective federal transportation programs by promoting collaborative efforts from all stakeholders.

As national transportation legislation develops, national leaders continue to emphasize the long-term national economic impacts related to developing and implementing a streamlined transportation network. According to TEA-21, transportation projects should "support the economic vitality of the metropolitan area, especially by enabling global competiveness, productivity, and efficiency" (U.S. Department of Transportation 2008). In a global economy, transportation officials must account for how the transportation system will influence the economic development and growth of a region. However, this national motivation to propel the transportation network forward can be hindered by local, re- gional and state issues. During the implementation of transportation plans, and during actual design and construction of transportation facilities, conflicts and competing ideas often emerge at the local level.

\subsection{The bottom-up approach: Local implications}

Specific implementation issues related to highway projects can cause contention and conflict. Before a facility is actually constructed, transportation planners are required by NEPA to investigate impacts due to a project's implementation. For example, before a corridor is approved, state transportation officials are required to identify the potential social, economic, and environmental effects associated with the facility's construction. The EIS is the legally required documentation of the technical concepts, purpose and need, projected impacts, corridor alternatives, and recommendations toward the final decision made by the Federal Highway Administration (FHWA).

The process of preparing an EIS can expose stark contrasts between national legislative policies and local socioeconomic, cultural, and environmental issues. For example, developers and commercial interests emphasize the potential economic impacts associated with an improvement or the construction of a highway project. Conversely, environmental and cultural resource agencies focus on the environmental and cultural impacts that may result from the same transportation actions. Conflicts may emerge because stakeholders will either gain or lose something if/when the highway is constructed.

Because local actors at the community, regional, or state levels may have intimate knowledge of the physical or political landscape, their influence into the process can either help or hinder certain initiatives and policies. To address tensions and differing values during the implementation process, the authors used a multi-criteria decision making (MCDM) approach. The following section presents a background of the model as well as how data was integrated. Lastly, the authors illustrate a prototype of the model utilized in this research.

\section{Technologies to improve modern transportation planning}

In transportation, delays to projects are frequently due to opposition, conflicting interests and differing opinions, and value judgments by stakeholders, resource agencies, planning organizations, and others. From the federal freight analysis to cultural and environmental impacts in local communities, 
transportation corridors address multiple goals, multiple factors, and consequently multiple impacts (negative and positive).

\subsection{Multi-criteria decision making}

Realistic decision-making problems are too complex to be addressed based on a single criterion or a narrow perspective. Multiple actors coupled with multiple (and sometimes conflicting) regulations create an atmosphere of tension if not outright conflict. Due to the many factors affecting the decisionmaking process, the lack of a unique solution and the plurality of opinions, computational tools can aid in conflict resolution and support decision making. MCDM offers a framework wherein differing opinions, priorities and values may be dealt with in a structured process that considers decision factors, ranks factor criteria, and allocates weights to factors so that results reflect the appropriate priority of each factor considered (Sadasivuni et al. 2009).

Multi-Criteria Decision Making describes a body of theories and strategies originating with the work of Vilfredo Pareto, particularly his optimal strategy to aggregate opposing criteria into a single index, first presented in 1896 (Eisenring et al. 2000). Despite strong roots in economics and business management, modern MCDM has branches in other areas such as human resources, environmental management, energy planning, and marketing. These different application fields have given rise to a variety of MCDM implementation techniques, which Pardalos et al. (1995) classify into in four categories: multi-objective mathematical programming, the preference-disaggregation approach, the outranking-relations approach, and multi-attribute utility theory.

The decision making involved in transportation planning can employ techniques from the "European School," which developed robust theories that emphasize the consideration of both positive and negative aspects for the criteria in order to obtain the best calculation of the relative weights of the alternatives (Pastijn and Leysen 1989). However, gathering negative and positive inputs from decision makers, stakeholders, and experts may be a difficult task compared to a simple ranking of preferred alternatives. In this case, the Analytical Hierarchy Process proposed by Saaty (1980) presents a simple but functional solution. Pastijn and Leysen (1989) state: "In contrast with this approach there is the so-called American School in which Saaty plays an important role with his 'Analytical Hierarchy Process' (AHP) Method in which there is no place for incomparabilities."

The Analytical Hierarchy Process is a method for multicriteria decision making that employs decision analysis math- ematics in different hierarchical levels to determine the priorities of various alternatives using pair-wise comparisons of different decision elements with reference to a common criterion. According to Saaty (Saaty 1994), AHP "can be used to make direct resource allocation, benefit/cost analysis, resolve conflicts, design, and optimize systems." Belton (1986) described Saaty's Analytic Hierarchy Process as a robust approach that is suited to wide use in practice.

Conceptually, MCDM can be implemented based on different approaches. Advances in informatics and spatial information provide a wide range of core-solutions. However, AHP is becoming one of the most common methods of coupling decision-making processes and geospatial analysis. In fact, AHP is the simplest decision making method to be prototyped that provides accurate results given a multitude of complementing and conflicting values (Kamrani and Nasr 2006). In geospatial analysis, AHP has become popular due to its straightforward implementation and positive results (Nobrega et al. 2009; Sadasivuni et al. 2009). These characteristics served as the basis for this research to develop a simple but functional geospatial AHP-based decision-making framework which serves as a mechanism that ranks inputs and produces output maps input ranking-output maps mechanism facilitating decision making at different levels. The core mechanism is a geospatial analysis structure that combines geographic information and critical input values towards graphic deliverables that represent the best-feasible solutions regarding conflicting values.

The research goal is to reproduce the traditional corridor planning-alignment definition as developed for the I269 through MCDM-AHP. Geographic Information Systems (GIS) and MCDM are combined to provide a multiscale framework supporting the mechanization of the process (Figure 2).

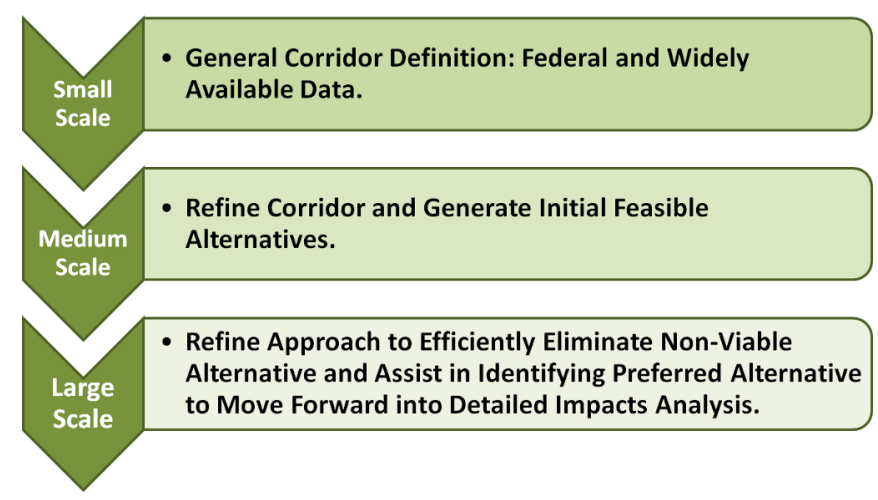

Figure 2: Top-down approach proposed by NCRST-SEPP. 


\subsection{Geographic Information Systems}

As previously discussed, more factors and attributes have to be considered in transportation planning decision-making processes today than in past decades. Context sensitive design, smart growth, and sustainability have become key factors in the planning and design of modern transportation projects. GIS are among the instruments used to modernize the process.

Geographic Information Systems are capable of handling massive amounts of data. In a broad perspective, the key mechanism of GIS is its ability to combine and analyze spatial information. Different types of information are layered and combined geographically in a "McHargian approach." So the overlay, spatial relationship and computer-based capabilities permit complex analysis and reports. Figure 3 illustrates different spatial data layered to compute a route between two sites.

When coupled with physical or economic models, GIS may be employed to transform and manipulate spatial and attribute data as needed to express values for evaluation criteria, such as the cost of different alternatives, population exposure to different levels of health risk, and the distribution of road network concentrations in different areas of a city.

In the sphere of transportation, GIS has been widely used in various areas, from planning to management. However, the transportation planning process is constantly evolving in response to the dynamics of land use, policy implementation, and economic and environmental impacts. Today, sustainability is frequently specified as a target for transportation projects, requiring assessment of environmental and socioeconomic impacts as well as risk assessment (Nobrega et al. 2009). GIS and decision-making frameworks are vital to encapsulate and process all these constraints. We hypothesize that the interaction between decision makers, public participation, and transportation planners is an essential element of the transportation planning process that can be enhanced though an interactive GIS-based MCDM.

Sadagopan (2000) states that the integration of interactive maps, audio, text, video, and other forms of community or city related data with analytical tools could help the public access and understand information. Similarly, Nobrega et al. (2009) note the importance of the stakeholders and decision makers on understanding inputs and outputs about the GIS-based decision-making process.

\subsection{Prototyping a tool based on AHP-MCDM and GIS}

Aiming to connect the theoretical AHP-GIS models within real demands from transportation planners, two minor mod- ifications are proposed in Nobrega (2009) and Nobrega and O’Hara (2009) regarding interactions among transportation practitioners:

- A direct ranking from decision makers and stakeholders to avoid pair-wise inputs (Figure 4);

- A scale-adaptive MCDM approach that makes it possible to combine factors and criteria in different levels within the decision-making process.

The overall goal is to make MCDM accessible and useful from both top-down and bottom-up perspectives in transportation planning. Making a GIS-based decision-making method understandable and available to transportation practitioners is one of the key goals of the SEPP project. Thus, the proposed MCDM framework utilizes rankings as inputs instead of pair-wise comparisons for factors and attributes according to the different hierarchical levels. The reasons are:

- Pair-wise comparison is an exhausting task when a large amount of criteria and factors is required;

- a ranking list of the preferred factors and criteria speeds up the process; and

- ranking is more suitable than pair-wise comparison for public participation.

The system is designed to simplify the decision-making processes. The core solution is flexible and suitable for use at different scales. From the top-down standpoint, the factors and attributes are on macro transportation and economic issues, whereas the bottom-up perspective considers a diversity of local issues regarding the positive and negative possible impacts of the transportation corridor. In practice, the MCDM-GIS framework is designed to streamline and enhance the NEPA process, agency coordination, and public participation. The authors evaluated this tool in the context of the planning process for the I-269 corridor near Memphis, Tennessee. The following section presents an overview of the "complexification" of the corridor. By identifying federal, regional, and local perspectives, the authors highlight the various values that emerge during the implementation process.

\section{Case study: The I-69/I-269 corridor}

\subsection{Federal Perspectives}

Interstate Highway 69 is a national project that will connect Canada and Mexico. The highway includes eight states from 


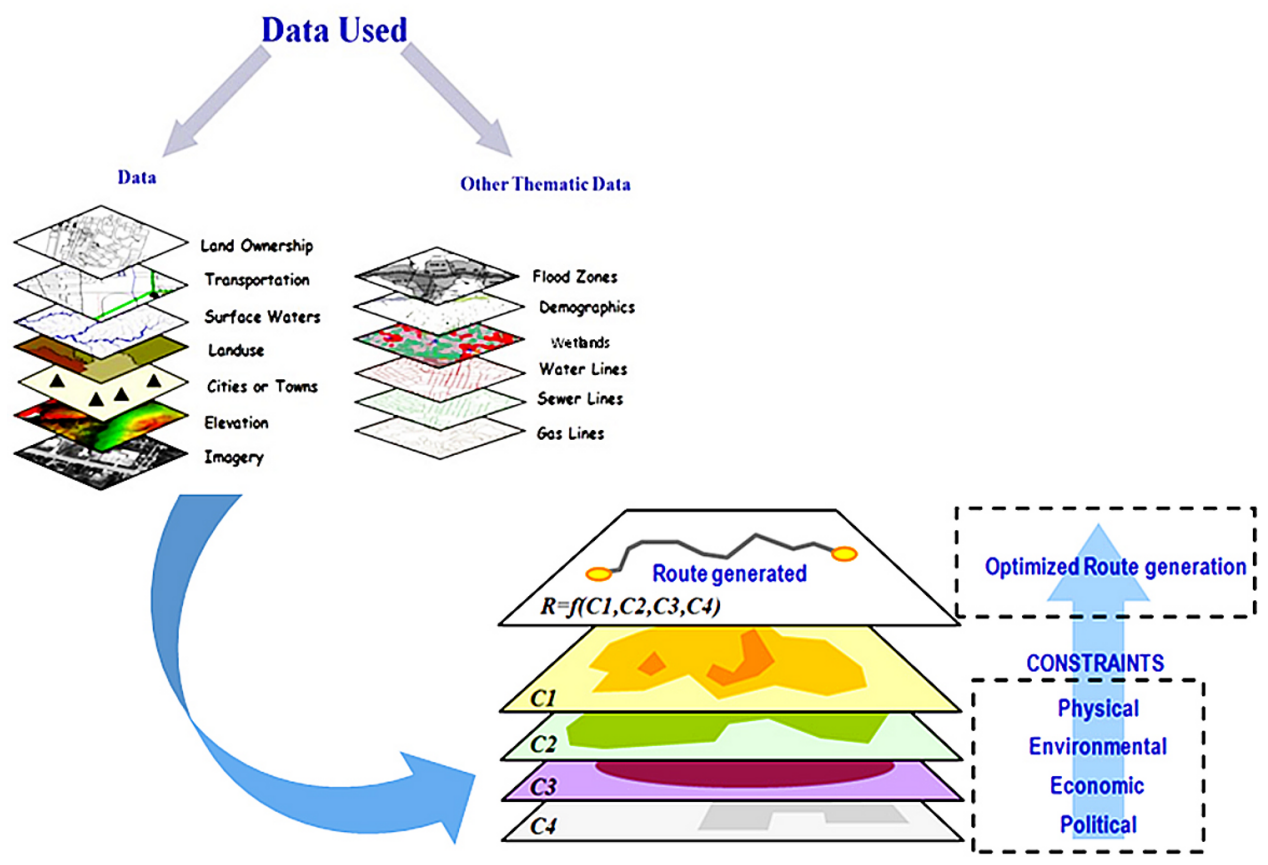

Figure 3: Typical use of GIS, integrating different types of data from a variety of sources to compute an optimal route.

tional Consortium for Remore sensing in Transportation UNDERSTANDING SPATIAL MULTI-CRITERIA DECISION MAKING an analytical demonstration of MCDM-AHP and how to is used in GIS

\section{Real world needs: ranking instead pair-wise inputs}
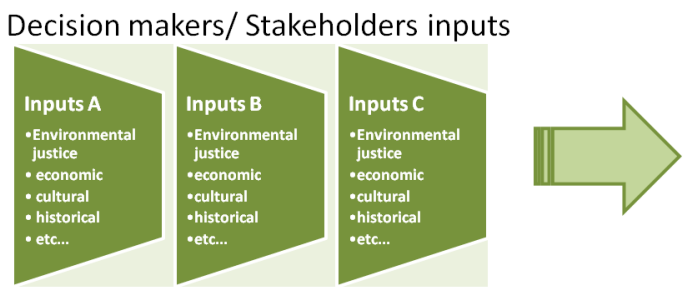

Pair-wise comparisons

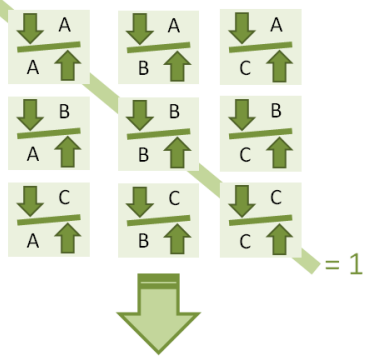

Ranking of alternatives

Normalization \& consistency ratio
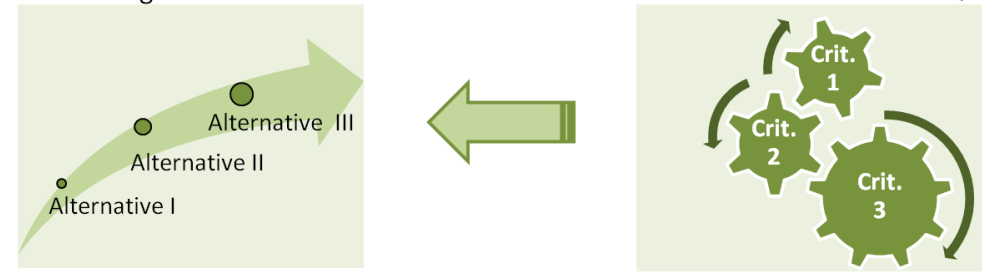

MSU-NGRST-SEPP MEMPHIS-IN-MAY WORKSHOP MOY $61-815,2009$ MOMPAIS-IN

Figure 4: Proposed MCDM flowchart for transportation planning (Nobrega 2009). 
the Gulf of Mexico and Texas Golden Triangle, through the Mississippi Delta, the Midwest, to the industrial north and finally to Canada. The states included in the entire project are Arkansas, Indiana, Kentucky, Louisiana, Michigan, Mississippi, Tennessee, and Texas (Figure 5).

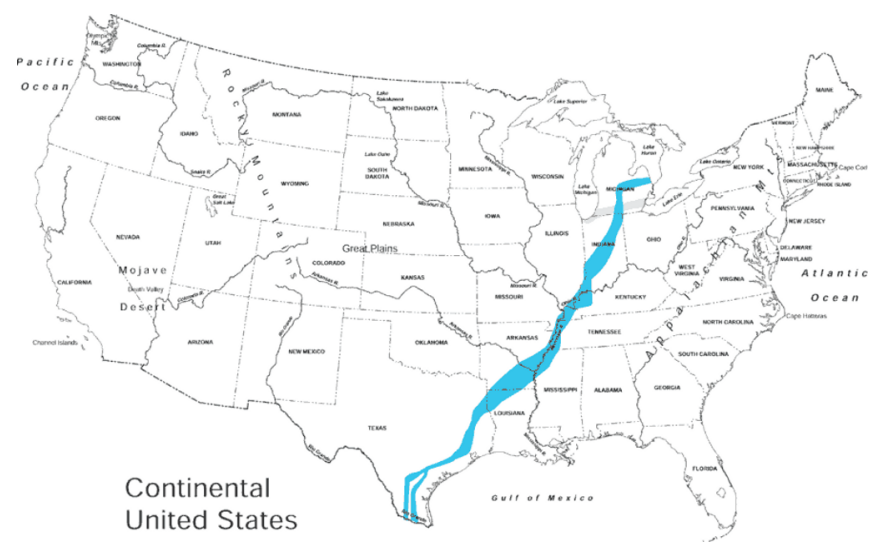

Figure 5: The I-69 national corridor.

The proposed I-69, which was "designed by Congress in the Intermodal Surface Transportation Efficiency Act of 1991 (ISTEA) to connect major cities and enhance economic development" (U.S. Department of Transportation 2006, 1), is a significant transportation project that potentially will alter the trade flow within North America. After the enactment of the North American Free Trade Agreement of 1992 (NAFTA), the trade community projected a significant increase in trade flow from Mexico and Canada to the United States. With these projections, TEA-21 (signed into law June 9,1999 ) officially authorized and prioritized I-69 as a national interstate project.

According to the Federal Highway Administration, the overall defined purpose of I-69 is:

"To improve international and interstate trade in accordance with national and state goals; to facilitate economic development in accordance with state, regional, and local policies and plans, and to improve surface transportation consistent with national, state, regional, and local needs with the Congressional designation of the corridor" (U.S. Department of Transportation 2006, 3).

\subsection{I-269: Regional Perspectives}

The 1600-mile national interstate project was divided into 32 Sections of Independent Utility (SIUs). Each SIU is subject to design and evaluation by the transportation agency of the state in which the SIU is located. The SIUs were designated in "...a manner consistent with FHWA Memorandum dated November 3, 1993 on establishing logical termini, and have been approved for advancement to the FHWA NEPA decision-making process" (U.S. Department of Transportation 2006, 4). The separation of the project into SIUs was intended to enable state DOTs to concentrate on state and local needs, as well as to identify scheduling deadlines and funding constraints.

SIU \#9 will accommodate traffic demands between Hernando, Mississippi, and Millington, Tennessee, reusing the existing I-55. However, because it traverses the metropolitan area of Memphis, Tennessee, a new I-269 is proposed to bypass Memphis to the east. The length of I-269 is approximately 44 miles. According to the Mississippi Department of Transportation (MDOT) and the Tennessee Department of Transportation (TDOT), the purpose of I-269 is to “... increase the accessibility of the region, stimulate economic development, respond to local traffic growth and travel demands of the public by providing high speed access-controlled facility that is responsive to traffic usage, reduce travel time by providing needed roadway links, improve safety, and enhance access between communities and routes within the I-69 corridor" (U.S. Department of Transportation 2006, 6).

As a segment of I-69, the development and construction of I-269 assists in addressing national initiatives. At the regional level, the purpose of I-269 in the context of SIU \#9 is to reduce congestion caused by increases in local traffic volume and regional travel demand by providing a high speed, access-controlled facility that is responsive to traffic usage and enhances access between communities and routes within the I-69 corridor.

To construct the I-269 corridor, a "systems approach" was adopted. A systems approach connects existing and proposed interstates and other existing and proposed major highways in a transportation network. Using this approach, MDOT determined that an outer loop around eastern Memphis was needed to accommodate traffic demand and to accomplish highlighted objectives. According to the analysis reported in (U.S. Department of Transportation 2006, iv), the project's objectives also include:

- To add 45 miles of new highway and connect 55 miles of existing highway;

- to enhance mobility by providing northbound and southbound travelers with an alternative route to avoid bottleneck and existing congestion; and

- to provide regional transportation access to the smaller cities and municipalities around Memphis. 
By adding general lanes and upgrading the current highway, the I-269 corridor is projected to increase access to cities and industrial parks near Memphis; the corridor is also expected to improve the connectivity of multiple highways, potentially reducing the likelihood of congestion.

\subsection{Local perspectives}

Although the national purpose of this corridor emphasizes the movement of international freight, enhancement of potential economic development opportunities, and potential traffic efficiencies, transportation planners are faced with multilevel and multidisciplinary decisions. The following highlights the "complexification" of modern day transportation policy implementation; because transportation project can have dramatic affects on the local community, planners are tasked with identifying a community's resources and values. These highlighted community resources have varied associated values depending on the stakeholder domain in question. These value judgments may affect the alignment patterns of a corridor.

For example, for the I-269 corridor, transportation officials conducted eight "early" pubic involvement meetings and four public hearings in locations throughout the study area. The meetings highlighted the purpose of and need for I-269. In addition, transportation planners probed for feedback regarding local concerns and issues that may result from the construction of I-269. According to the U.S. DOT,

"Concerns expressed by the public included increased air and noise pollution, impacts to neighborhoods and schools, wetlands, and archeological sites and historical resources, safety, loss of property, amplified urban sprawl, lower property values, the transportation of hazardous materials, and the creation of a drug traffic corridor" (U.S. Department of Transportation 2006, 241).

Overall, 1180 individuals attended the four public hearings. The analysis indicates that the local citizens were overwhelmingly concerned about the potential economic development opportunities associated with the new transportation corridor. At the public hearing in Southaven, Mississippi, several comments were made about the overall positive economic impact of the project. In addition to public hearings, 456 responses were received by the transportation planners. These responses were concerned with impacts to neighborhoods and schools, property values, noise and air pollution, flooding, urban sprawl, and loss of wetlands and agricultural fields. These differences between the values expressed by public participants and the values expressed by other stakeholders regarding the implementation of a transportation corridor can develop into a contentious impasse that requires signifi- cant resources and often lengthy litigation to achieve resolution. Figure 6 illustrates typical meetings between transportation practitioners involved in the I-269 corridor project and local community.

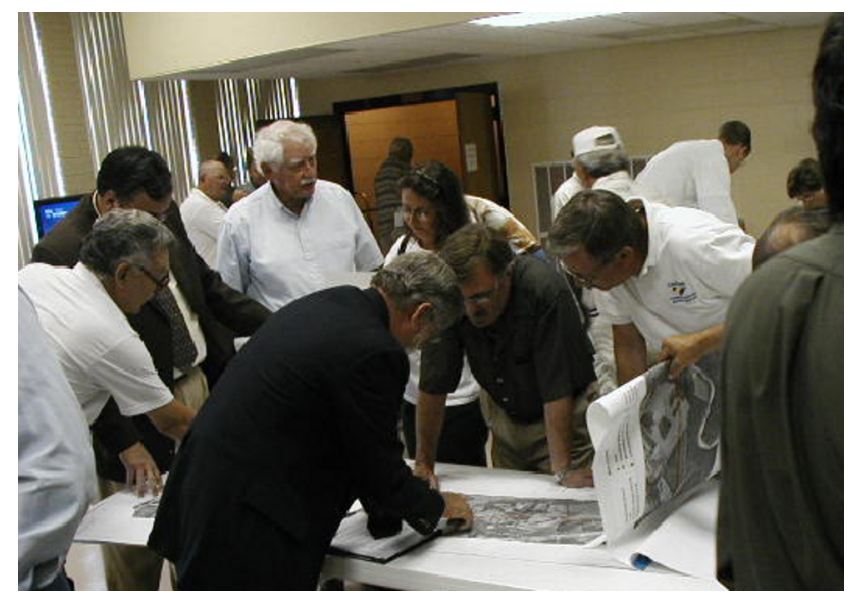

(a) Millington, TN (June 21, 2004).

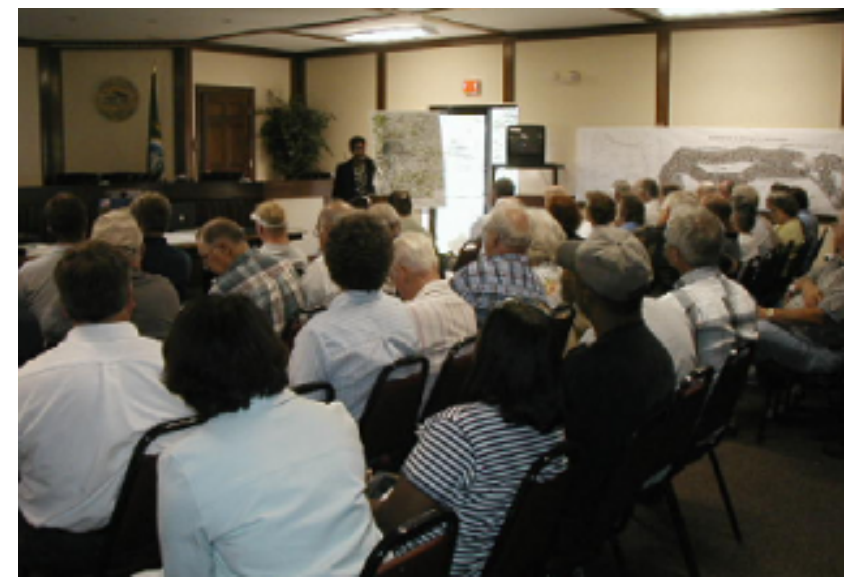

(b) Byhalia, MS (June 28, 2004).

Figure 6: I-269 public hearings.

The remainder of this paper highlights how MCDM can be utilized as a decision-making framework that can help transportation planners prioritize the values between national and local stakeholders and facilitate the interaction with local citizens. The authors applied the framework to the I-269 planning and alignment process to streamline biophysical, socioeconomic and cultural elements considered in the decision making process. The following section highlights how the MCDM model would be beneficial for planners to identify stakeholder values and prioritize them for project implementation. 


\section{Findings: Applying MCDM to the I-269 corridor}

Once the transportation professionals and resource agency personnel input their respective priorities, multiple corridor alignment scenarios can be displayed. Figure 7 shows how differing priorities produce differing alignments in a simple scenario. The brown path illustrates the selected alignment as designed by transportation practitioners from MDOT and TDOT; the other three are based on MCDM scenarios, designed automatically as GIS-based least-cost paths. All three MCDM paths prioritize avoiding urban areas, so all three paths run south of the Memphis area; however, the prioritization of the other variables shifts the alignment substantially. In Path 1 , avoidance of urban areas was valued the strongest (over $60 \%$ of weighting), while the other variables were assigned substantially lower weights, resulting in the southernmost path. Path 2 still gives the highest priority to urban avoidance, but does not prioritize this variable as highly as Path 1. Additionally, Path 2 values avoidance of water (rivers, streams, lakes, and ponds). Therefore, Path 2 shifts substantially north in order to avoid the water that Path 1 intersects frequently. Path 3 also values urban avoidance most, but assigns a much higher priority to wetland avoidance than Paths 1 or 2 . Thus, Path 3 shifts on the southwest side of the alignment off Path 1 for better wetland avoidance.

\subsection{Local perspectives}

The scale-adaptive MCDM approach streamlines the planning process by ranking appropriate factors and criteria across scales to optimize transportation project design. From a bottom-up standpoint, this can also take place in public information meetings and public hearings where participants can input their values into a computer and display a path that reflects their priorities for the project. Participants can view multiple options and then make a final selection. This provides an opportunity for both learning and involvement by members of the public. The scenarios created during public meetings can be included as part of the public comment section of an EIS, along with scenario options, frequency of scenario selection, and tabulation of participant priorities. Figure 8 illustrates how the priorities and values are integrated in a GIS-based MCDM process.

\subsection{Streamlining Environmental Review and Planning Process for NEPA}

Likewise, given that an EIS must approve one of the corridor alternatives or select the no-build alternative, scale-adaptive MCDM can benefit transportation engineers as well by assisting in the design of horizontal adjustments on the alignment. From the engineering perspective, the inputs should include, but not be limited to, soil type and condition, drainage, volume of cuts and fills, among others. Figure 9 shows that the cumulative low-cost corridor determined through the use of the MCMD model follows the final alignment of I-269 closely. The final alignment was designed after lengthy traditional EIS field work, which generated the parameters for comparative analysis and selection of the preferred alignment.

Based on the Final Environmental Impact Statement for SIU \#9 (U.S. Department of Transportation 2006), factors, criteria, and values were reproduced to serve as the basis for the development of the SEPP project. Our solution blends the hierarchical decision-making process (AHP) with multiscale geospatial analysis. Inputs ranged from freely available federal data to local county data provided by the Department of GIS of Desoto County, Mississippi. Figure 10 illustrates a visual comparison of the final alignment of I-269 in Desoto County and the corridor computed using GISbased MCDM. The 1000-foot corridor (white) encapsulates approximately 93 percent of the final alignment, demonstrating the feasibility of using the automated solution as preNEPA field work. This can substantially streamline the oftenprotracted NEPA process by identifying a narrow corridor on which resource staff can focus.

\section{Discussion and conclusions}

GIS and MCDM are becoming key components in modern transportation corridor planning. These technologies were used to create a prototype decision-support tool that can be utilized in the policy implementation phase of the policy process. The ability of this tool to combine top-down and bottom-up approaches facilitates deliberative dialogue and conflict resolution. However, the use of advanced technology does not fit easily into simplistic policy process models. Insight into policy analysis and the policy paradox of decision making can be found in the work of policy scholars such as Deborah Stone, who notes, "By and large, academic writing disparages politics as an unfortunate obstacle to good policy... I believe we are all political creatures, in our daily lives as well as in our governance, and I wanted to construct a mode of pol- 


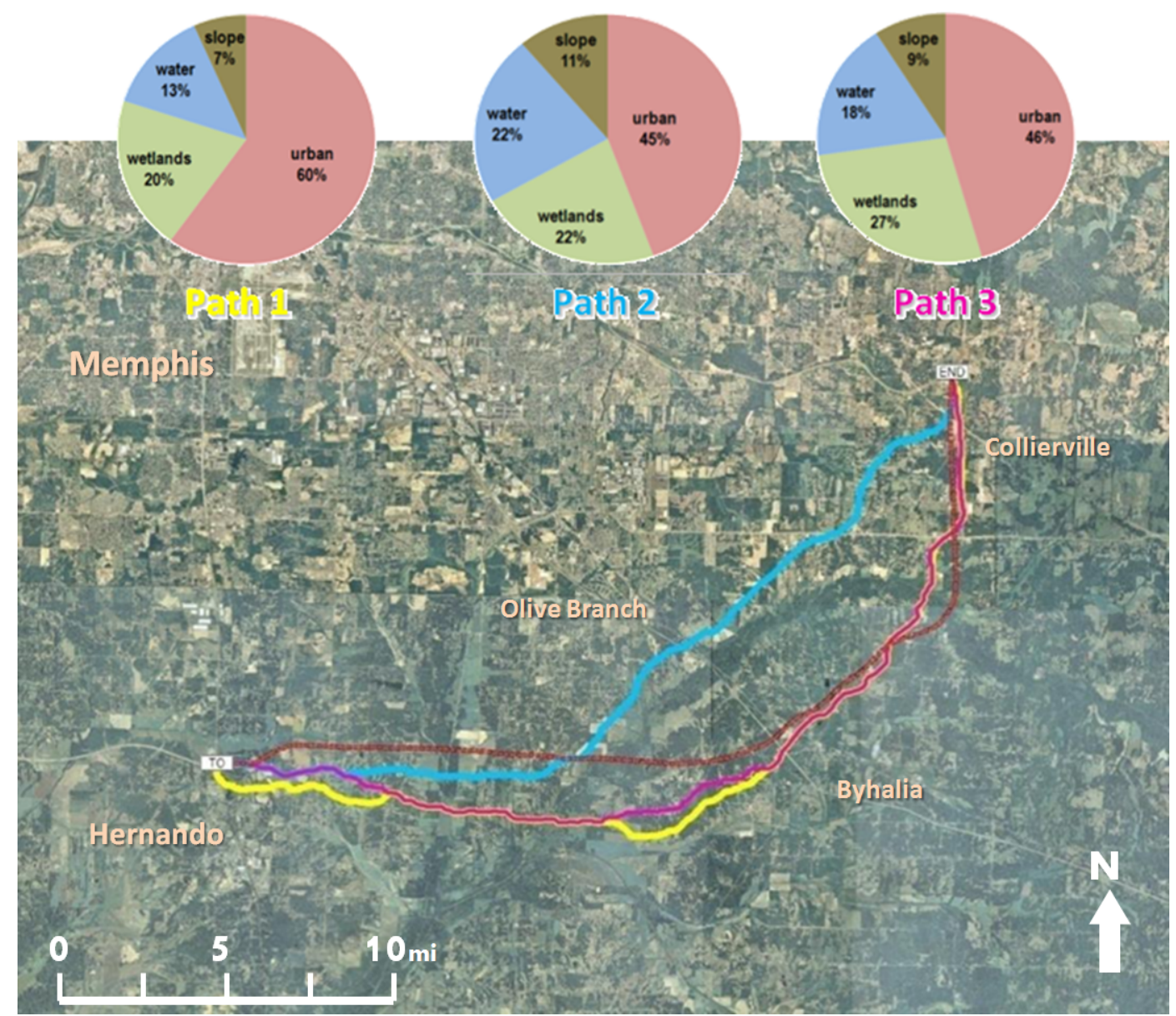

Figure 7: Example of GIS-MCDM output. Alignments generated for regional corridor segment near Memphis, Tennessee.

icy analysis that accepts politics as a creative and valuable feature of social existence" (Stone 1998).

Though Stone's work focuses on policy analysis instead of policy implementation, she also notes, "The field of policy analysis is dominated by economics and its model of society as a market. A market, as conceived in classical microeconomics, is a collection of atomized individuals who have no community life. They have independent preferences, and their relationship consist entirely of trading with one another to maximize their individual well being... I do not find the market model a convincing description of the world I know or, for that matter, any world I would want to live in" (Stone 1998).

These ideals can be applied to transportation policy implementation theories as well. As technology advances and MCDM methods improve, new models can and should be created to move the policy field forward. Using this case study as an example, theorists should discuss implementation as it actually occurs, using a model of political community in which both administrators and citizens can work toward both the public interest as well as individual interests. Such models can account for how people value and prioritize conflicting issues, not just assume that individual preference is the "sole" driving force. Without these advances in policy process models, including policy creation, implementation and analysis, transportation professionals will continue to suffer under poorly crafted legislation in a complex and often adversarial environment.

As Congress debates corporate bailouts, stimulus packages and financial crisis, global warming, economics, health care reform, homeland security, and national defense, it seems unlikely that the implementation of public policies will become any easier. The increasing complexity of local, state, national, and international issues requires new policy implementation ideas, theories, and tools. These new policies will be both top-down and bottom-up implementation challenges. The lengthy and complex history of transportation policy in the United State provides multiple opportunities for case study analysis that could result in multiple innovations for public 


\section{Combining Inputs}
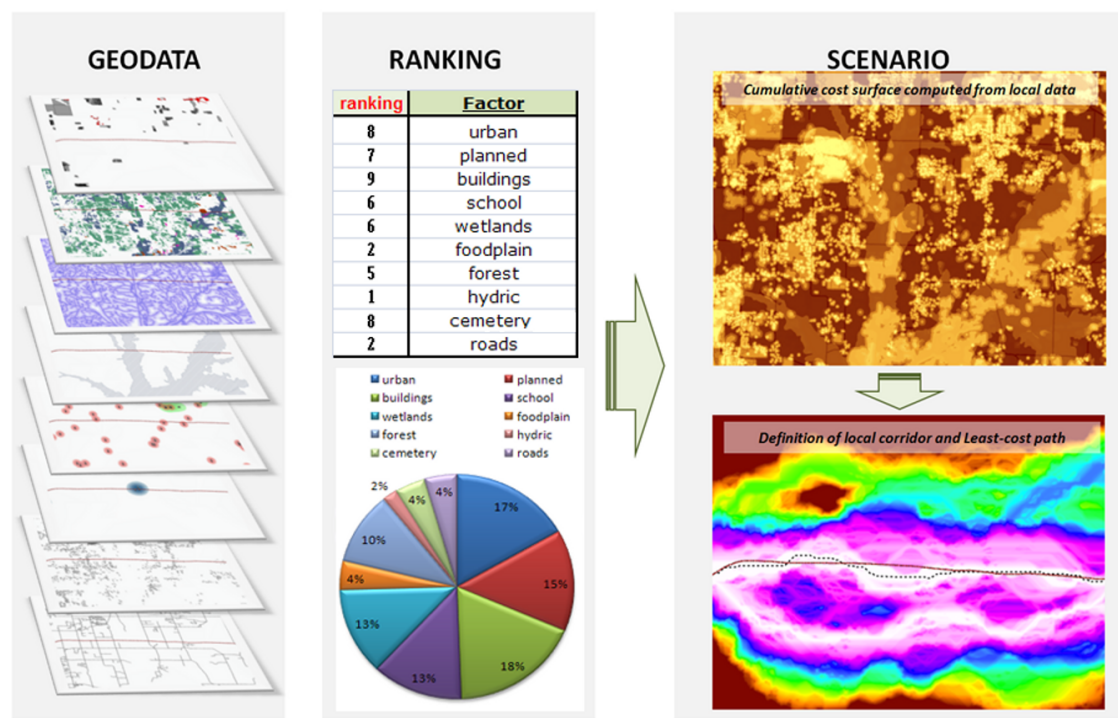

Figure 8: Local implications and hypothetical rankings (adapted from Nobrega and O’Hara 2009).

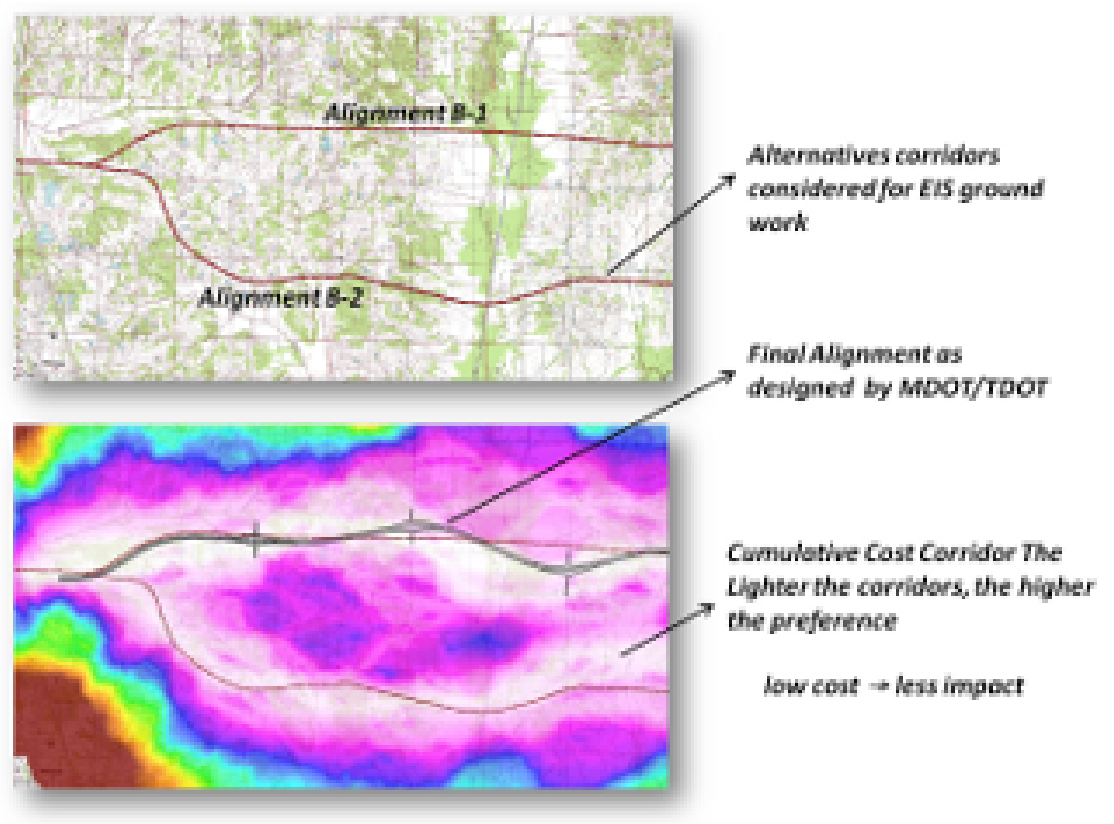

Figure 9: Horizontal adjustments and definition of preferred alignment based on local inputs. 


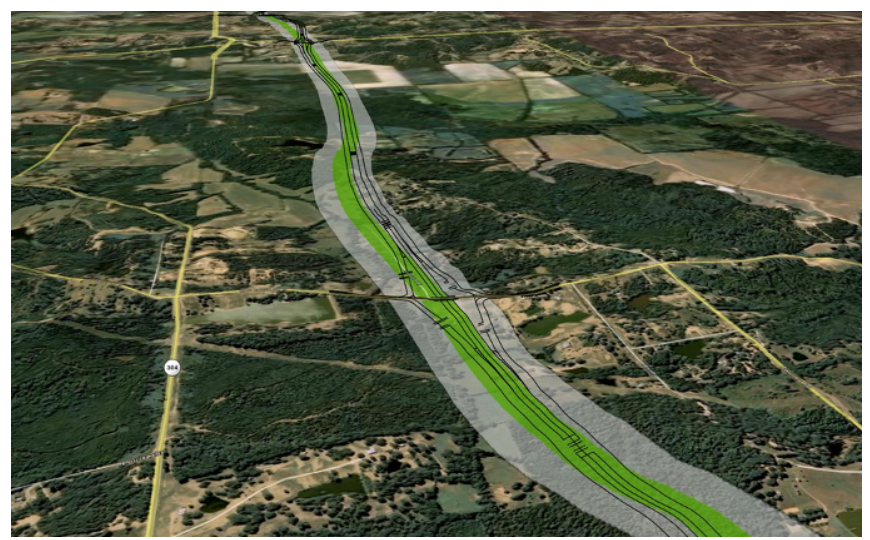

Figure 10: Overlay of the final SEPP 1000-foot (white) corridor and 300-foot (green) corridor and the proposed I-269 (black). Background source: Google Earth.

policy modeling and advancement. Future research in this area is necessary.

Policy regulations exist, as well as geospatial and decision making technology, to support transportation planning projects. Understanding the complexity of public policy implementation and the real use of the large body of academic knowledge about GIS-based MCDM in transportation planning still depend on extensive clarifications and integration with existing practices in transportation planning. This article highlights the need for demystification of the policies and technologies to aid efficiency in modern transportation planning. The SEPP project used a flexible method that delivered diverse alternatives according to different input factors and attributes in its decision-making process. The corridors produced from the SEPP project are similar to the EIS-approved corridor of I-269 using traditional methods. Given the positive aspects of the SEPP research, as well as the applicability of the method as an innovative solutios for transportation policy and planning streamlining, the methodology should be assembled into a toolkit that could be disseminated to state departments of transportation.

\section{Acknowledgements}

The authors wish to thank the Mississippi Department of Transportation (MDOT) and the Tennessee Department of Transportation (TDOT) for partnering and contributing to the research project. Special thanks to the Department of GIS of the Desoto County in Mississippi, for providing the impressive collection of geodata for our local analysis.

This project was made possible by funding and support from the U.S. Department of Transportation - Research and
Innovative Technology Administration (USDOT-RITA) Cooperative Agreement DTOS59-07-H-0004. The views, opinions, and statements contained in this article are solely those of the authors and do not represent the official policy or position of the Department of Transportation or the Research and Innovative Technology Administration.

\section{References}

Bailey, S. and E. Mosher. 1968. ESEA; the Office of Education Administers a Law. Syracuse, New York: Syracuse University Press.

Beimborn, E. and R. Puentes. 2003. Highways and Transit: Leveling the Playing Field in Federal Transportation Policy. The Brookings Institution Series on Transportation Reform. Washington, DC: The Brookings Institution Center on Urban and Metropolitan Policy. URL http://www.brookings.edu/ /media/Files/rc/reports/ 2003/12metropolitanpolicy_beimborn/20031215_ Beimborn.pdf.

Belton, V. 1986. A comparison of the analytic hierarchy process and a simple Multi-Attribute value function. European Journal of Operational Research, 26(1):7-21. doi: 10.1016/0377-2217(86)90155-4.

Birkland, T. 2005. An Introduction to the Policy Process: Theories, Concepts, and Models of Public Policy Making. New York: M.E. Sharpe, 2nd edition.

Derthick, M. 1970. Defeat at fort lincoln. The Public Interest, 20:3-39. URL http://www.nationalaffairs.com/public interest/detail/defeat-at-fort-lincoln.

Eisenring, M., L. Thiele, and E. Zitzler. 2000. Conflicting criteria in embedded system design. Design \& Test of Computers, IEEE, 17(2):51-59. doi: 10.1109/54.844334.

Kamrani, A. and E. Nasr, eds. 2006. Rapid Prototyping: Theory and Practice. Number 6 in Manufacturing Systems Engineering Series. New York: Springer.

Lipsky, M. 1971. Street-Level bureaucracy and the analysis of urban reform. Urban Affairs Quarterly, 6(4):391-409. doi: 10.1177/107808747100600401.

Nobrega, R. 2009. Understanding Spatial-Criteria decision making: An analytical demonstration of AHP-based MCDM and how it is used in GIS. In National Consortium for Remote Sensing in Transportation (NCRST) Annual Workshop. Memphis: NCRST/Geosystems Research Institute. URL http://www.gri.msstate.edu/publications/docs/2009/ 05/5939MCDM1_undestanding\%20AHP.pdf. 
Nobrega, R. and C. O'Hara. 2009. NCRST/SEPP implementation of MCDM and results of i269 case study. In National Consortium for Remote Sensing in Transportation Memphis in May Workshop. Memphis: NCRST/Geosystems Research Institute. URL http://www.ncrste.msstate.edu/sepp_workshops/ memphis_may_2009.html.

Nobrega, R., C. O'Hara, R. Sadasivuni, and J. Dumas. 2009. Bridging Decision-Making process and environmental needs in corridor planning. Management of Environmental Quality, 20(6):622-637. doi: 10.1108/14777830910990744.

Pardalos, P., Y. Siskos, and C. Zopounidis, eds. 1995. Advances in Multicriteria Analysis. Number 5 in Nonconvex Optimization and its Applications. Dordrecht: Kluwer Academic Publishers.

Pastijn, H. and J. Leysen. 1989. Constructing an outranking relation with ORESTE. Mathematical and Computer Modelling, 12(10):1255-1268. doi: 10.1016/08957177(89)90367-1.

Saaty, T. 1980. The Analytical Hierarchy Process. New York: McGraw-Hill.

Saaty, T. 1994. Fundamentals of Decision Making and Priority Theory with the Analytic Hierarchy Process. Number 6 in The analytic hierarchy process series. Pittsburgh, PA: RWS Publications.

Sadagopan, G. 2000. Web-Based Geographic Information Systems: Public Participation in Virtual Decision Making Environments. Ph.D. thesis, Virginia Polytechnic Institute and State University, Blacksburg, VA.

Sadasivuni, R., C. G. O'Hara, R. A. A. Nobrega, and J. Dumas. 2009. A transportation corridor case study for MultiCriteria decision analysis. In Proceedings: American Society of Photogrammetry and Remote Sensing Annual Conference. Baltimore, MD. URL www.asprs.org/a/publications/ proceedings/baltimore09/0082.pdf.

Stone, D. 1998. Policy Paradox: The Art of Political Decision Making. New York: Norton.

Tripp, J. and N. Alley. 2004. Streamlining NEPA's environmental review process: Suggestions for agency reform. New York University Environmental Law Journal, 12(1):74-110. URL http://www1.law.nyu.edu/journals/ envtllaw/issues/vol12/index.html.

U.S. Department of Transportation. 2006. Interstate 69, section of independent utility \#9, final environmental impact statement. Technical Report FHWA-TN-EIS-0401F, U.S. Department of Transportation. URL http:// www.tdot.state.tn.us/i69/segment9/Segment9EIS.pdf.
U.S. Department of Transportation. 2008. Transportation Equity Act of the 21st Century: Moving Americans into the 21st Century. URL http://www.fhwa.dot.gov/tea21/ index.htm.

Weingroff, R. 2001. Creating a landmark: The intermodel surface transportation act of 1991. Public Roads, 65(3):7-48. URL http://www.fhwa.dot.gov/ publications/publicroads/01 novdec/istea.cfm. 